\title{
The Impact of GLP-1 Receptor Agonists on Patients with Diabetes on Insulin Therapy
}

Janelle B. Gyorffy

San Antonio Uniformed Services Health Education Consortium

Andrea N. Keithler

San Antonio Uniformed Services Health Education Consortium

Jana L. Wardian PhD

University of Nebraska Medical Center, jana.wardian@unmc.edu

Lee A. Zarzabal

Defense Health Agency

Alexander Rittel

Defense Health Agency

See next page for additional authors

Tell us how you used this information in this short survey.

Follow this and additional works at: https://digitalcommons.unmc.edu/com_hosp_articles

\section{Recommended Citation}

Gyorffy, Janelle B.; Keithler, Andrea N.; Wardian, Jana L. PhD; Zarzabal, Lee A.; Rittel, Alexander; and True, Mark W., "The Impact of GLP-1 Receptor Agonists on Patients with Diabetes on Insulin Therapy" (2019). Journal Articles: Hospital Medicine. 28.

https://digitalcommons.unmc.edu/com_hosp_articles/28

This Article is brought to you for free and open access by the Hospital Medicine at DigitalCommons@UNMC. It has been accepted for inclusion in Journal Articles: Hospital Medicine by an authorized administrator of DigitalCommons@UNMC.For more information, please contact digitalcommons@unmc.edu. 


\section{Authors}

Janelle B. Gyorffy, Andrea N. Keithler, Jana L. Wardian PhD, Lee A. Zarzabal, Alexander Rittel, and Mark W. True 


\title{
THE IMPACT OF GLP-1 RECEPTOR AGONISTS ON PATIENTS WITH DIABETES ON INSULIN THERAPY
}

\author{
Janelle B. Gyorffy, MD"; Andrea N. Keithler, DO'; Jana L. Wardian, PhD'; \\ Lee A. Zarzabal ${ }^{3}$; Alexander Rittel ${ }^{3}$; Mark W. True, $M^{4}$
}

\begin{abstract}
Objective: The clinical benefit of adding a glucagonlike peptide-1 receptor agonist (GLP-1RA) to basal-bolus or very high dose insulin regimens is unclear. This study investigated the impact of adding a GLP-1RA to a spectrum of insulin regimens (basal, basal-bolus, and U-500) to determine the impact on hemoglobin $\mathrm{A} 1 \mathrm{c}(\mathrm{HbAlc})$, weight loss, and total daily insulin dose (TDD) over the course of 12 months.

Methods: A retrospective chart review was conducted on 113 participants with type 2 diabetes mellitus using insulin therapy. Each participant's HbA1c, body weight, and TDD were recorded prior to initiation of GLP-1RA therapy and at the 3,6, and 12-month time points while on combination therapy.

Results: Across all participants, the HbA1c values decreased significantly from a baseline of $8.9(74 \mathrm{mmol} /$ $\mathrm{mol}) \pm 0.14 \%$ to $8.2(66 \mathrm{mmol} / \mathrm{mol}) \pm 0.14 \%(P<.01)$ in the first 3 months, $8.0(64 \mathrm{mmol} / \mathrm{mol}) \pm 0.12 \%(P<.01)$ at 6 months, to $8.3(67 \mathrm{mmol} / \mathrm{mol}) \pm 0.14 \%(P<.01)$ at 12 months. There was no significant decrease in weight or TDD with the addition of a GLP-1RA overall or in differ-
\end{abstract}

Submitted for publication January 13, 2019

Accepted for publication April 25, 2019

From ${ }^{1}$ Internal Medicine, San Antonio Uniformed Services Health Education Consortium, San Antonio, Texas, ${ }^{2}$ Diabetes Center of Excellence, Wilford Hall Ambulatory Surgical Center, San Antonio, Texas, ${ }^{3}$ Solution Delivery Division, Defense Health Agency, San Antonio, Texas, ${ }^{4}$ Endocrinology, San Antonio Uniformed Services Health Education Consortium, San Antonio, Texas.

Address correspondence to Dr. Andrea Keithler, 3551 Roger Brooke Drive, San Antonio, TX 78234.

E-mail: andrea.n.keithler.mil@mail.mil.

Published as a Rapid Electronic Article in Press at http: / / www.endocrine practice.org on June 6, 2019. DOI: 10.4158/EP-2019-0023

To purchase reprints of this article, please visit: www.aace.com/reprints. Copyright (C) 2019 AACE. ent insulin groups. However, there was a clinically significant decrease in weight over the study duration.

Conclusion: The results of this study suggest that adding a GLP-1RA to various insulin regimens may help to achieve glycemic goals while avoiding the less desirable side effects of weight gain and increasing insulin regimens. However, the expected weight loss and decrease in TDD may not be as sizable in the clinical setting. (Endocr Pract. 2019;25:935-942)

\section{Abbreviations:}

DCOE $=$ Diabetes Center of Excellence; $\mathbf{D M}=$ diabetes mellitus; GLP-1RA = glucagon-like peptide-1 receptor agonist; HbA1c $=$ hemoglobin A1c; $\mathbf{R C T}=$ randomized controlled trial; TDD $=$ total daily dose

\section{INTRODUCTION}

Type 2 diabetes mellitus (DM) is a metabolic disorder characterized by a progressive decline in pancreatic beta cell function and insulin resistance, resulting in hyperglycemia. As the disease progresses, individuals typically develop increasing insulin requirements, starting with once-daily basal insulin alone, followed by more complex basal-bolus insulin regimens with short-acting bolus insulin given prior to meals. Some people with diabetes may eventually require such large doses of insulin that a more concentrated insulin preparation like U-500 regular insulin (5 times more concentrated) is necessary for glycemic control. Unfortunately, insulin therapy is associated with increased risks of weight gain and hypoglycemia and may undermine the ability to achieve glycemic control (1). The addition of alternative agents, such as glucagon like peptide-1 receptor agonists (GLP-1RAs), can improve glycemic control and lessen the negative aspects of increased insulin therapy.

This material is protected by US copyright law. To purchase commercial reprints of this article, visit www.aace.com/reprints. For permission to reuse material, please access www.copyright.com or contact the Copyright Clearance Center, Inc. (CCC). 
Numerous studies have investigated the use of GLP-1RAs with basal insulin therapy and have shown improved glycemic control and weight loss (2-8). In one trial of patients with inadequate control on basal insulin, the addition of exenatide resulted in a similar reduction in hemoglobin A1c (HbA1c); however, there was greater weight loss, less hypoglycemia, and greater patient satisfaction compared with the addition of bolus insulin (5). Two large meta-analyses of randomized controlled trials (RCTs) with over 15,000 participants enrolled, found that adding a GLP-1RA to basal insulin led to decreased HbA1c, weight loss, and similar rates of hypoglycemia compared to basal insulin alone. Additionally, when compared to traditional basal-bolus insulin regimens, these meta-analyses found that the GLP-1RA and basal insulin combination was superior, with greater $\mathrm{HbA} 1 \mathrm{c}$ reduction, better weight profile, and lower rates of hypoglycemia $(2,9)$. Given this favorable profile, the Federal Drug Administration approved the concurrent use of GLP-1RAs and basal insulin in 2011. Both the American Diabetes Association and American Association of Clinical Endocrinologists endorse the use of GLP-1RAs with basal insulin prior to starting bolus insulin.

Although the clinical benefit of adding a GLP-1RA to basal insulin appears to be clear, there is much less published data on the effects of adding GLP-1RAs to basal-bolus or very high-dose insulin regimens. The majority of published studies show a positive effect of combining GLP-1RAs with insulin therapy but do not differentiate between basal-bolus insulin and high-dose insulin regimens (10-12). A 2015 RCT of 124 participants using basal-bolus insulin regimens showed that the addition of GLP-1RAs was associated with a significant reduction in HbA1c, weight, and total daily insulin dose over placebo at 24 weeks (13). Another small RCT of 37 participants with a high insulin requirement (>100 units daily) compared the addition of a GLP-1RA to continued basal-bolus insulin therapy and showed statistically significant reductions in HbA1c, weight, and total daily dose (TDD) of insulin at 6 months, in favor of the GLP-1RA group (14). Although this preliminary evidence suggests the addition of a GLP-1RA to basal-bolus insulin and high-dose insulin therapy may be helpful, more research is needed.

The purpose of our study was to investigate the effects of GLP-1RAs in our population of individuals with type 2 DM using a spectrum of insulin regimens (basal insulin alone, basal-bolus insulin, and U-500 insulin) to determine the impact on $\mathrm{HbA} 1 \mathrm{c}$, weight loss, and TDD over the course of 12 months.

\section{METHODS}

\section{Study Design}

This was a retrospective study of individuals with diabetes using a GLP-1RA and insulin concurrently, from 2005 to 2014 in the San Antonio Military Health System. Our beneficiary population includes active duty and retired military personnel and their dependent family members. The electronic medical record was used to find individuals with a prescription for both a GLP-1RA and insulin during the study time frame. The data set was then narrowed to only evaluate participants enrolled in the U.S. Air Force Diabetes Center of Excellence (DCOE). The DCOE is comprised of a collaborative group of health care professionals, including endocrinologists, diabetes nurse practitioners, certified diabetes educators, exercise physiologists, and dieticians who work together to provide standardized diabetes care and education to beneficiaries within the military health system. Individuals who are enrolled at the DCOE have access to services provided by these support staff and many attend a set of standardized education classes in addition to meeting individually with a diabetes educator and nutritionist. The standardized system at the DCOE was an ideal source of information as these records were the most complete and had the most consistent documentation for collecting pertinent data.

Eligibility criteria included age $\geq 18$ years, diagnosis of type 2 DM, treatment with a GLP-1RA and insulin therapy concurrently, and enrollment at the DCOE. Exclusion criteria were the use of an insulin pump, pregnancy, and military basic trainees. The majority of participants in the study were military retirees and their dependents. Data were collected through chart review. Each subject's HbA1c, body weight, and TDD of insulin were recorded prior to initiation of GLP-1RA therapy, and at the 3,6, and 12-month time points while on combination therapy. Additionally, the number of hypoglycemic episodes and hospital admissions were recorded while participants were enrolled in the study. These data were self-reported by patients at appointments and were recorded within the standardized template used at the DCOE. Institutional research board approval was obtained prior to retrospective data collection.

\section{Statistical Analysis}

Data analysis was performed using SAS Version 9.4 (SAS Institute, Cary, NC). Primary outcomes of HbA1c, weight, and TDD were assessed for normality. Log transformation was applied to TDD which was utilized for all further modeling. Differences in mean $\mathrm{HbA1c}$, weight, and log-transformed TDD at baseline, 3, 6, and 12-month points were assessed with a repeated measures ANOVA with an autoregressive (1) covariance structure assumed. Models included fixed effects for time, insulin group (basal, basal-bolus, and U-500) and a time by insulin group interaction. Post hoc analysis was conducted to determine insulin group differences at each time point with a TukeyKramer multiple testing correction applied.

\section{RESULTS}

There were 235 participants with type $2 \mathrm{DM}$ who were using insulin and started on a GLP-1RA while enrolled in the DCOE during the study period. Of the charts reviewed, 
113 met the inclusion criteria and 122 were excluded due to missing data points (84 subjects) or stopping the GLP-1RA (36 subjects). Participants had a mean age of 57 years, $60 \%$ were women and $44 \%$ were Caucasian. The mean starting $\mathrm{HbA} 1 \mathrm{c}$ was $8.9(74 \mathrm{mmol} / \mathrm{mol}) \pm 0.14 \%$, the mean starting weight was $100.03 \pm 1.80 \mathrm{~kg}$, and the mean starting TDD was $96.14 \pm 10.77$ units (Table 1 ). Within the study population, there were 47 participants using basal insulin only, 54 participants using basal-bolus insulin, and 12 participants using U-500 insulin. The GLP-1RAs taken in the study were exenatide $(5 \mathrm{mcg}$ twice daily, $10 \mathrm{mcg}$ twice daily, $2 \mathrm{mg}$ weekly) or liraglutide (0.6 mg, $1.2 \mathrm{mg}, 1.8 \mathrm{mg}$ ). Subjects may have switched between GLP-1RAs or undergone dose adjustments during the study time period (Table 2). All analyses were done using an individual's baseline insulin group, and further review showed that $85 \%$ (96 patients) remained in the same insulin groups. There were only 11 hypoglycemic events reported and no hospitalizations for hypoglycemia during the study period. All hypoglycemia and hospitalization were self-reported by the patients.

Across all participants, the HbA1c values decreased significantly from a baseline of $8.9(74 \mathrm{mmol} / \mathrm{mol}) \pm 0.14 \%$ to $8.2(66 \mathrm{mmol} / \mathrm{mol}) \pm 0.14 \%(P=.003)$ in the first 3 months, $8.0(64 \mathrm{mmol} / \mathrm{mol}) \pm 0.12 \%(P<.01)$ at 6 months, and $8.3(67 \mathrm{mmol} / \mathrm{mol}) \pm 0.14 \%(P<.01)$ at 12 months. In the basal insulin group $(n=47)$, there was a significant decrease in $\mathrm{HbA} 1 \mathrm{c}$ from a baseline of $9.0(75 \mathrm{mmol} / \mathrm{mol}) \pm$ $0.24 \%$ to $8.2(66 \mathrm{mmol} / \mathrm{mol}) \pm 0.20 \%(P<.001)$ at 3 months and to $7.9(63 \mathrm{mmol} / \mathrm{mol}) \pm 0.17 \%(P<.001)$ at 6 months,

\begin{tabular}{|c|c|c|}
\hline \multicolumn{3}{|c|}{$\begin{array}{c}\text { Table } 1 \\
\text { Study Demographics }\end{array}$} \\
\hline \multicolumn{3}{|l|}{ Sex } \\
\hline Men & 53 & $47 \%$ \\
\hline Women & 60 & $53 \%$ \\
\hline \multicolumn{3}{|l|}{ Race } \\
\hline Caucasian & 44 & $39 \%$ \\
\hline African American & 20 & $18 \%$ \\
\hline Asian & 8 & $7 \%$ \\
\hline Other & 28 & $25 \%$ \\
\hline \multirow[t]{2}{*}{ Unknown $^{\mathrm{a}}$} & 13 & $11 \%$ \\
\hline & Mean & Standard error \\
\hline Age & 57 years & 1.04 \\
\hline Baseline $\mathrm{HbA} 1 \mathrm{c}$ & $8.9 \%(74 \mathrm{mmol} / \mathrm{mol})$ & 0.14 \\
\hline Baseline Weight & $100.73 \mathrm{~kg}$ & 4.00 \\
\hline Baseline TDD & 96.14 units & 10.77 \\
\hline \multicolumn{3}{|c|}{$\begin{array}{l}\text { Abbreviations: } \mathrm{HbA} 1 \mathrm{c}=\text { hemoglobin } \mathrm{A} 1 \mathrm{c} ; \mathrm{TDD}=\text { total daily } \\
\text { dose. } \\
\text { aRace was not required to be reported and participants whose } \\
\text { race was unknown may have declined to comment and/or their } \\
\text { race was not recorded within the record system. }\end{array}$} \\
\hline
\end{tabular}

but there was no significant difference at 12 months (8.3 [67 $\mathrm{mmol} / \mathrm{mol}] \pm 0.23 \%[P=.25])$. In the basal-bolus insulin group $(\mathrm{n}=54)$, there was a significant change from a baseline of $8.7(72 \mathrm{mmol} / \mathrm{mol}) \pm 0.20 \%$ to $8.0(64 \mathrm{mmol} / \mathrm{mol})$ $\pm 0.19 \%(P=.007)$ at 3 months, and $8.0(64 \mathrm{mmol} / \mathrm{mol})$ $\pm 0.19 \%(P=.01)$ at 6 months. There was no significant difference at 12 months $(8.0[64 \mathrm{mmol} / \mathrm{mol}] \pm 0.17 \%[P=$ $.07])$. In the $\mathrm{U}-500$ group $(\mathrm{n}=12)$, there was no significant decrease from a baseline of $9.1(76 \mathrm{mmol} / \mathrm{mol}) \pm 0.29 \%$ to $9.2(77 \mathrm{mmol} / \mathrm{mol}) \pm 0.49 \%(P=1.00)$ at 3 months, $8.5(69$ $\mathrm{mmol} / \mathrm{mol}) \pm 0.41 \%(P=.99)$ at 6 months, and to $9.3(78$ $\mathrm{mmol} / \mathrm{mol}) \pm 0.39 \%(P=1.00)$ at 12 months (Fig. 1$)$.

Across all participants, the mean weight did not significantly decrease from a baseline of $100.03 \pm 1.80 \mathrm{~kg}$ to $98.87 \pm 1.99 \mathrm{~kg}(P=.94)$ at 3 months, $98.93 \pm 2.05 \mathrm{~kg}$ $(P=.95)$ at 6 months, and to $98.70 \pm 1.84 \mathrm{~kg}(P=.91)$ at 12 months. Although not statistically significant, the overall trend did show a decrease in weight that plateaued at the 12-month endpoint. In the basal insulin group $(n=47)$ there was no significant decrease from a baseline weight of $97.97 \pm 2.69 \mathrm{~kg}$ to $99.05 \pm 3.30 \mathrm{~kg}(P=.95)$ at 3 months, $98.90 \pm 3.22 \mathrm{~kg}(P=1.0)$ at 6 months, or to $97.34 \pm 2.82$ $\mathrm{kg}(P=.99)$ at 12 months. In the basal-bolus insulin $(\mathrm{n}=$ 57) group there was no significant decrease from a baseline weight of $100.30 \pm 2.69 \mathrm{~kg}$ to $98.22 \pm 2.74 \mathrm{~kg}(P=$ $.3)$ at 3 months. There was a significant decrease to 97.37 $\pm 3.10 \mathrm{~kg}(P=.024)$ at 6 months, but an increase to 98.70 $\mathrm{kg} \pm 2.70 \mathrm{~kg}(P=.59)$ at 12 months. In the U-500 group $(\mathrm{n}=12)$ there was no significant decrease in weight from a baseline of $111.30 \pm 4.27 \mathrm{~kg}$ to $102.81 \pm 6.08 \mathrm{~kg}(P=.99)$ at 3 months, $105.91 \pm 4.50 \mathrm{~kg}(P=1.0)$ at 6 months, and to $105.84 \pm 5.49 \mathrm{~kg}(P=.76)$ at 12 months (Fig. 2$)$.

Across all participants, the TDD did not significantly decrease from a baseline of $96.14 \pm 10.77$ units to 91.37

\begin{tabular}{|l|c|}
\hline \multicolumn{2}{|c|}{ Insulin and GLP-1 Subgroups } \\
\hline Insulin Groups \\
\hline Basal insulin & $47(42 \%)$ \\
\hline Basal-bolus insulin & $54(48 \%)$ \\
\hline U-500 insulin & $12(10 \%)$ \\
\hline GLP-1 & \\
\hline Exenatide 5 mcg twice daily & $18(16 \%)$ \\
\hline Exenatide 10 mcg twice daily & $49(43 \%)$ \\
\hline Exenatide 2 mg weekly & $63(55 \%)$ \\
\hline Liraglutide 0.6 mg daily & $14(12 \%)$ \\
\hline Liraglutide1.2 mg daily & $6(5 \%)$ \\
\hline Liraglutide 1.8 mg daily & $2(2 \%)$ \\
\hline $\begin{array}{l}\text { Abbreviation: GLP-1 = glucagon-like peptide 1. } \\
\text { aParticipants may have switched to another GLP-1 agonist } \\
\text { or undergone dose adjustment during the study period. } \\
\text { Note: Due to missing data, not all totals are 100\%. }\end{array}$ \\
\hline
\end{tabular}




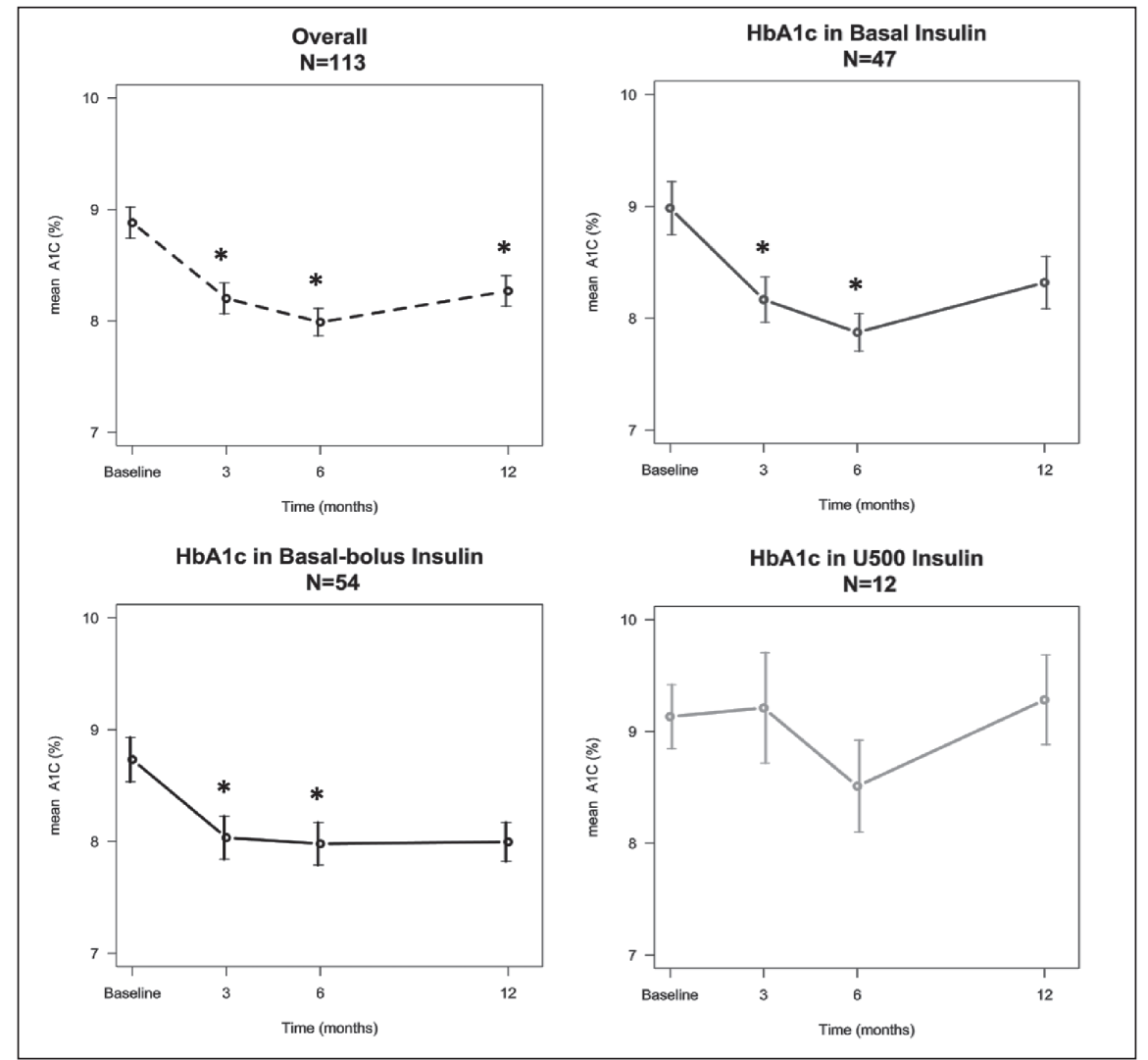

Fig. 1. Changes in HbA1c over 12 months after initiating GLP-1 by insulin group. Results are for the mean \pm standard error. Statistical analysis is by repeated measures ANOVA for difference of the mean at baseline versus 3 months, 6 months, and 12 months. Errors bars are 95\% CIs. $C I=$ confidence interval; $G L P-1=$ glucagon-like protein $1 ; H b A l c=$ hemoglobin A1c. $* P<.05$ between baseline comparison.

\pm 10.86 units $(P=.99)$ at 3 months, $95.64 \pm 11.3$ units at 6 months $(P=.87)$, and then increased to $109.45 \pm 14.85$ units at 12 months $(P=.28)$. In the basal insulin group (n $=47$ ) there was a significant increase in TDD at all time points from a baseline of $32.12 \pm 3.77$ units to $34.97 \pm$ 3.77 units at 3 months $(P=.003)$, to $39.92 \pm 3.65$ units at 6 months $(P<.001)$, to $48.34 \pm 4.95$ units $(P<.0001)$ after the addition of a GLP-1RA. In the basal-bolus insulin group ( $\mathrm{n}=54)$ there was no significant decrease in TDD from a baseline of $104.65 \pm 7.27$ units to $94.81 \pm 7.28$ units $(P$ $=.55)$ at 3 months, to $96.07 \pm 8.39$ units $(P=.94)$ at 6 months, to $101.77 \pm 7.23$ units $(P=1.00)$ at 12 months. In the U-500 group $(n=12)$, there was no significant decrease in TDD from a baseline of $308.58 \pm 64.50$ units, to $299 \pm$ 69.93 units $(P=1.00)$ at 3 months, to $328.89 \pm 61.17$ units $(P=.99)$ at 6 months, to $382.75 \pm 105.55$ units $(P=.99)$ at 12 months (Fig. 3).

\section{DISCUSSION}

In this retrospective study, the addition of a GLP-1RA to all types of insulin therapy was associated with a significant decrease in HbA1c at the 3, 6, and 12-month time points compared to baseline. There did not seem to be differences in the effect of GLP-1RAs on HbA1c between the basal and basal-bolus insulin subgroups. When evaluating for HbA1c changes, the basal, basal-bolus, and U-500 insulin groups had the greatest decline at the 3- and 6-month time points. Although there was no significant decrease at the 12-month time point from baseline in the basal and basal-bolus insulin groups, it was lower. In the U-500 group, there was a nonsignificant increase in HbA1c from baseline at the 12-month time point. This suggests that the greatest effect of a GLP-1RA on HbA1c may occur in the first 6 months and may provide some stabilization in the long term. It is possible that a greater long-term reduction in $\mathrm{HbA} 1 \mathrm{c}$ may be seen with further titration and optimization of GLP-1RA dosing, as some patients in this study were not on maximal doses.

Our study did not demonstrate an overall significant decline in weight at any time point with the addition of a GLP-1RA; however, there was a decreasing trend from baseline that stabilized at the 12-month time point. The basal insulin group actually had an increase in weight at the 3- and 6-month time point, whereas the basal-bolus insulin group had a significant decrease in weight at the 6-month time point only. The U-500 group had a nonsignificant decline in weight at all time points. However, at 


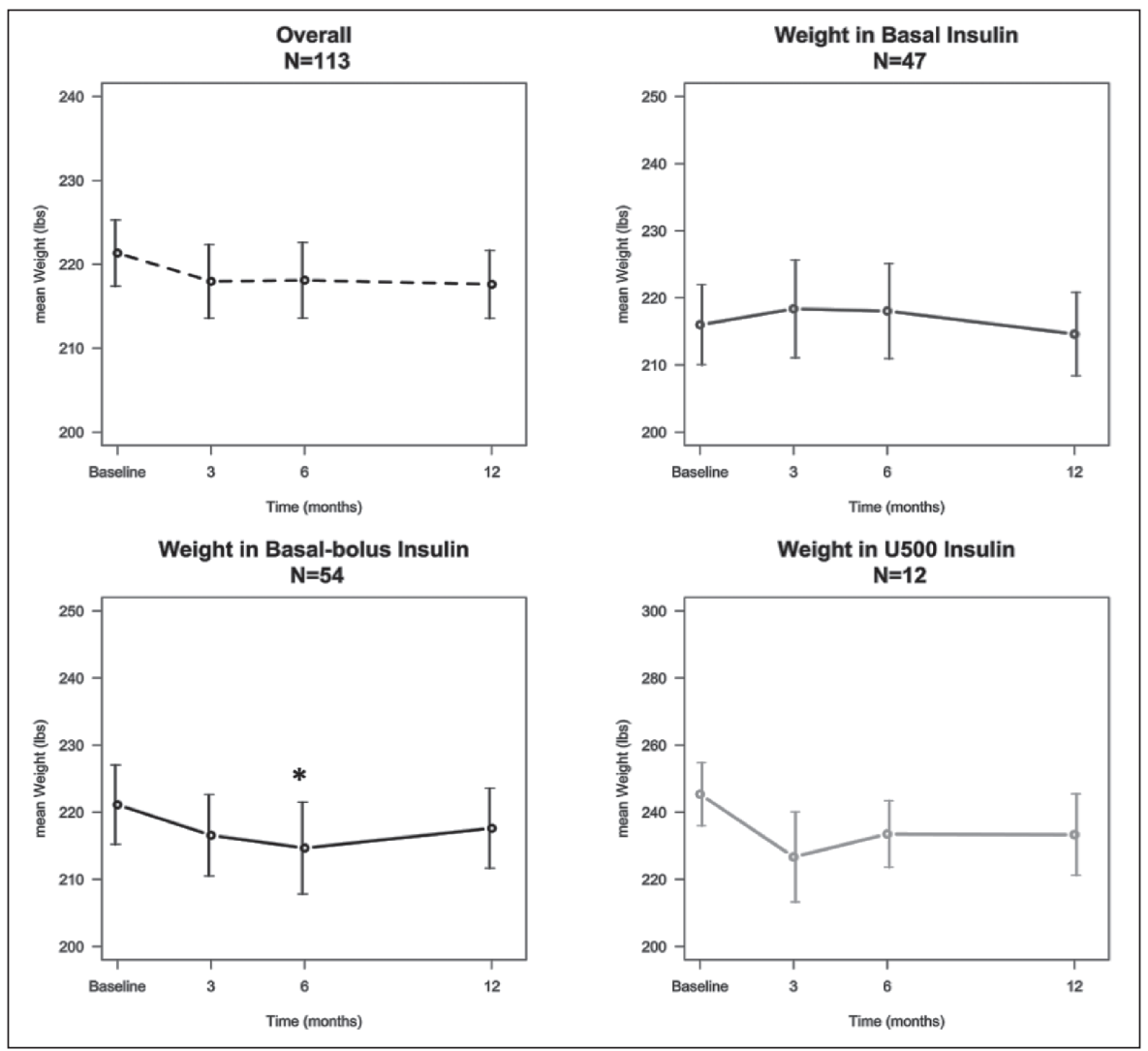

Fig. 2. Changes in weight over 12 months after initiating GLP-1 by insulin group. Results are for the mean \pm standard error. Statistical analysis is by repeated measures ANOVA for difference of the mean at baseline versus 3 months, 6 months, and 12 months. Errors bars are 95\% CIs. $C I=$ confidence interval; $G L P-I=$ glucagon-like protein $1 . * P<.05$ between baseline comparison.

12 months, all groups had a nonsignificant decrease in weight from their baseline. While this study failed to show statistical significance, the clinical significance cannot be discounted, as these weight decreases transpired even in the setting of rising insulin doses.

This study did not find a significant decline in TDD at any time point after starting a GLP-1RA. The basal insulin group had a significant increase at all time points whereas the basal-bolus and U-500 insulin groups had a nonsignificant decline at 3 and 6 months, but an increase at 12 months. In fact, the overall trend at 12 months amongst all insulin groups showed a rising trend in insulin doses from baseline.

There are very few studies evaluating GLP-1RA on individuals with type 2 DM using U-500 insulin. In our study, the U-500 insulin group did not show a statistically significant decline in $\mathrm{HbA1c}$, weight, or TDD, which may have been due to the small sample size of only 12 participants. In the literature, Pantalone et al (15) reported a $>50 \%$ U-500 insulin reduction, a decrease in HbA1c by $2.1 \%(23 \mathrm{mmol} / \mathrm{mol})$, and a weight loss of $26.2 \mathrm{~kg}$, and Lane et al (16) reported a decreased in HbAlc 1.4\% (15 $\mathrm{mmol} / \mathrm{mol}$ ), a decrease in weight of $5.1 \mathrm{~kg}$, and a TDD reduction of $28 \%$ after the addition of liraglutide. Our data does not demonstrate the same degree of improvement as these studies, suggesting that more research is needed in the category of high insulin doses and GLP-1RA use in a real-world clinical setting.

Our study also did not show the expected decrease in weight and TDD compared with what has been reported in the literature $(10,12,16,17)$. One reason for this may be due to the characteristics of the population in the study. Generally, people enrolled in the DCOE have long standing uncontrolled diabetes and failed primary care management. The baseline demographics in Table 1 demonstrate the poor control and high insulin requirements of the study population. The efficacy of GLP1-RAs is dependent on insulin production, so it is possible that our study population with advanced type $2 \mathrm{DM}$ had decreased beta cell function and may not have been able to maintain a sustained response to the GLP-1RA. Additionally, many of these participants were likely not on optimal insulin dosing at the start of the study and therefore would have needed increased insulin doses despite the addition of a GLP-1RA. Finally, this study looked at the effects of a GLP-1RA over 12 months which is a longer timeframe than typically reported in the literature, and thus other studies may have failed to capture these results because they stopped at an earlier time point. 


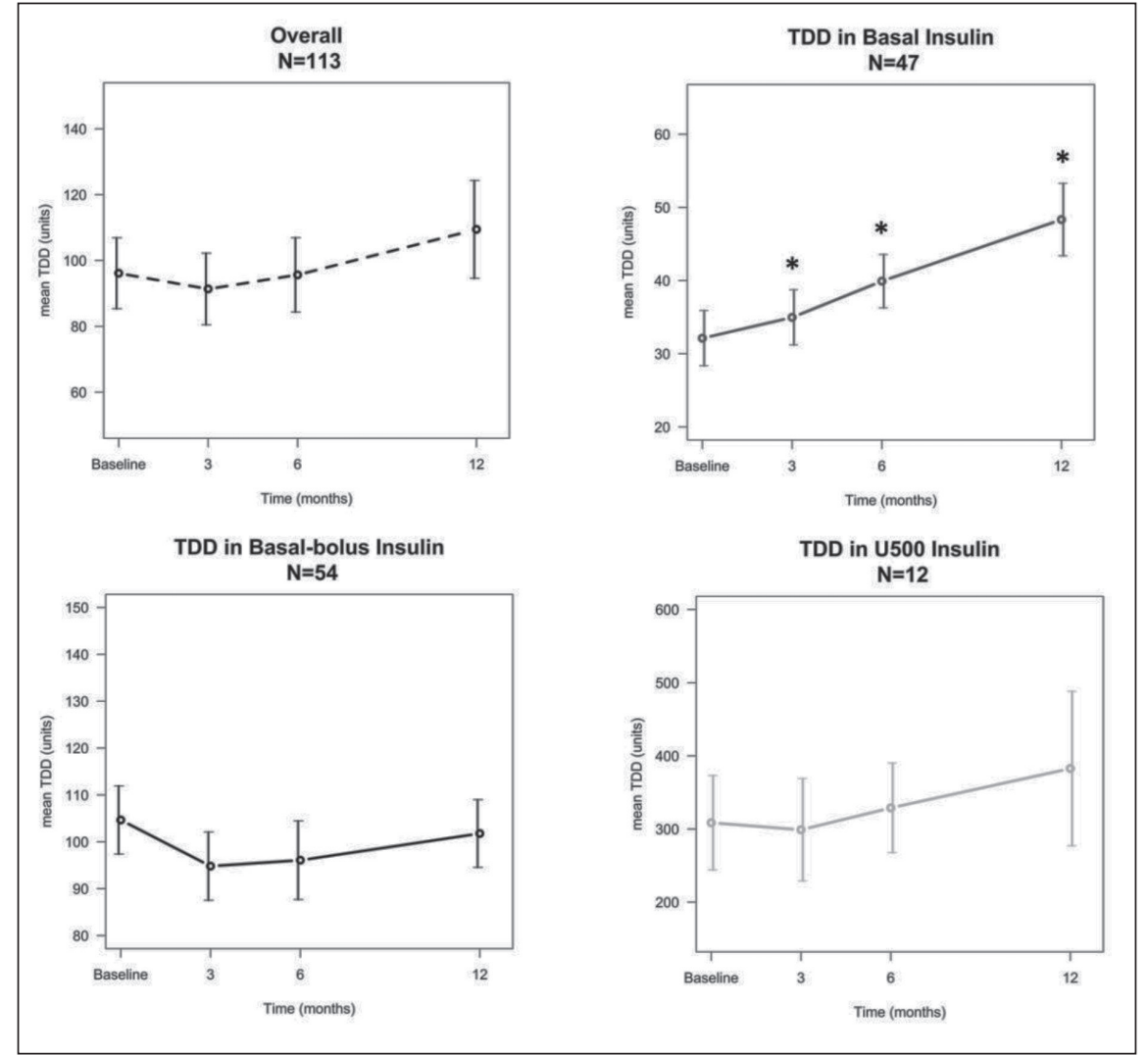

Fig. 3. Changes in total daily dose (TDD) of insulin over 12 months after initiating GLP-1 by insulin group. Results are for the mean \pm standard error. Statistical analysis is by repeated measures ANOVA for difference of the mean at baseline versus 3 months, 6 months, and 12 months. Errors bars are 95\% CIs. $G L P-1=$ glucagon-like protein $1 . * P<.05$ between baseline comparison.

There are some studies that show a comparable increase in weight and TDD with the addition of a GLP-1RA. In a similar retrospective study, Yoon et al (10) reported an increase in weight that occurred after 18 months and no significant change in TDD after 12 months of GLP-1RA and insulin therapy. However, there was no differentiation made in the study between basal insulin and basal-bolus insulin groups. The RCT of Buse et al (18) where exenatide or placebo was added to long acting insulin found an increase in TDD in both groups, though it was greater in the placebo group (20 units/day versus 13 units/day). Seino et al (11), also did not report a significant change in weight after 36 weeks of GLP-1RA therapy with insulin, though the study population baseline BMI was near normal $\left(25.6 \mathrm{~kg} / \mathrm{m}^{2}\right)$. The results of these studies and ours suggest that the effect of GLP-1RA on weight and TDD may not be as robust as initially reported, especially with longer duration of GLP-1RA use.

The results of our study may be more aligned with a "real world" scenario as it considers adherence, actual use, and response to a GLP-1RA. Generally, participants in our study were started on a GLP-1RA because they had such poor control, which may not have been the case in clinical trials. While our study population had access to standard- ized diabetes education classes, individual sessions with diabetes educators, and nutrition counseling, their participation in these services was not required. Our study did not specifically provide any additional counseling, nutrition guidance, or lifestyle interventions that many studies incorporated (12). As this was a retrospective study, our participants may not have received a comparable level of education or possessed the same motivations compared to participants in a clinical trial. Although this study did not show the expected results in terms of weight loss and decrease in TDD, it may be a more realistic representation of the effects of a GLP-1RA on individuals with type 2 DM.

The strengths of this study include the diversity of insulin regimens prescribed to participants, including U-500 insulin, and long duration compared with previous studies of similar design. While the number of participants was comparable to other studies of this nature, there were relatively few individuals within each subgroup. This was a limitation to our study and future studies with a greater number of participants within each insulin group would be beneficial. As this study was retrospective, the data represent real world outcomes and reflect participant adherence and physician clinical decision making. A major limitation 
of the study was its retrospective design, which did not allow for clearly defined intervention groups or a control group. The data necessary to generate a matched control group for this study were not readily available. Also, some participants underwent dose changes or were switched to an alternate GLP-1RA during the study period which was not accounted for. All data were obtained through medical record review which may have questionable accuracy and there was no way to ensure adherence. It is unknown if changes to oral antihyperglycemics were made during the study period which may have affected results. Additionally, the study population was largely comprised of participants taking exenatide and therefore the results may not be generalizable to other GLP-1RAs.

The results of this study question the current belief that the addition of a GLP-1RA to insulin therapy will promote weight loss and decrease TDD. This benefit may not extend to all people with type 2 DM, as factors such as increasing insulin resistance, poor adherence, lack of additional supportive resources, and financial barriers may not be accounted for in current clinical trials. As cost can be a prohibiting factor for GLP-1RA use, a better understanding of the expected benefits or lack thereof may help patients and providers create a cost-conscious treatment plan. There could potentially be responders versus nonresponders to GLP-1RAs, though there are no means for identification at this time. Additional studies to identify such individuals could allow providers to target those expected to have a substantial response. Furthermore, there are no clear guidelines on the optimal duration of GLP-1RA and insulin therapy and most of the currently available data only account for relatively short-term use. More studies are required to examine the clinical implications and treatment strategies of adding a GLP-1RA to various insulin therapies, particularly in people with poorly controlled diabetes requiring more aggressive treatment regimens.

\section{CONCLUSION}

In this study, the addition of a GLP-1RA to various insulin regimens was associated with a significant decrease in HbA1c overall, but there was no statistically significant change in weight or TDD. The addition of a GLP-1RA to basal-bolus insulin in participants with poorly controlled type 2 DM may help to achieve glycemic goals while avoiding the less desirable side effects of weight gain and increasing insulin regimens. However, the expected improvement in weight and TDD may be less in a real-world setting and in people with long standing disease requiring higher insulin doses than have previously been reported in the literature. The successful use of advanced and complex treatment regimens requires the support of a multidisciplinary team with readily accessible specialists, diabetes educators, and nutritionists. More studies are needed to better evaluate the long-term effects and durability of GLP-1RAs, especially in people with poorly controlled diabetes requiring high doses of basal-bolus insulin.

\section{ACKNOWLEDGMENT}

We would like to thank Dianna Holub and Stanley Kuzbiski for their assistance in data management and study logistics.

\section{DISCLOSURE}

The authors have no multiplicity of interest to disclose. The views expressed are those of the authors and do not reflect the official policy of the Department of the Air Force, the Department of the Army, the Department of Defense or the United States Government.

\section{REFERENCES}

1. Inzucchi SE, Bergenstal RM, Buse JB, et al. Management of hyperglycaemia in type 2 diabetes: a patient-centered approach. Position statement of the American Diabetes Association (ADA) and the European Association for the Study of Diabetes (EASD). Diabetologia. 2012;55:1577-1596.

2. Eng C, Kramer CK, Zinman B, Retnakaran R. Glucagon-like peptide-1 receptor agonist and basal insulin combination treatment for the management of type 2 diabetes: a systematic review and meta-analysis. Lancet. 2014;384:2228-2234.

3. Dalal M, Xie L, Baser O, DiGenio A. Adding rapid-acting insulin or GLP-1 receptor agonist to basal insulin: outcomes in a community setting. Endocr Pract. 2015;21:68-76.

4. Buse JB, Bergenstal RM, Glass LC, et al. Use of twice-daily exenatide in basal insulin-treated patients with type 2 diabetes: a randomized, controlled trial. Ann Intern Med. 2011;154:103-112.

5. Diamant $\mathbf{M}$, Nauck MA, Shaginian $\mathbf{R}$, et al. Glucagon-like peptide-1 receptor agonist or bolus insulin with optimized basal insulin in diabetes. Diabetes Care. 2014;37:2763-2773.

6. Mathieu C, Rodbard HW, Cariou B, et al. A comparison of adding liraglutide versus a single daily dose of insulin aspart to insulin degludec in subjects with type 2 diabetes (BEGIN: VICTOZA ADD-ON). Diabetes Obes Metab. 2014;16:636-644.

7. Charbonnel B, Bertolini M, Tinahones FJ, Domingo MP, Davies M. Lixisenatide plus basal insulin in patients with type 2 diabetes mellitus: a meta-analysis. J Diabetes Complications. 2014;28:880-886.

8. Riddle MC, Aronson R, Home P, et al. Adding once-daily lixisenatide for type 2 diabetes inadequately controlled by established basal insulin: a 24-week, randomized, placebo-controlled comparison (GetGoal-L). Diabetes Care. 2013;36:2489-2496.

9. Maiorino MI, Chiodini P, Bellastella G, Capuano A, Esposito K, Giugliano D. Insulin and glucagon-like peptide 1 receptor agonist combination therapy in type 2 diabetes: a systematic review and meta-analysis of randomized controlled trials. Diabetes Care. 2017;40:614-624.

10. Yoon NM, Cavaghan MK, Brunelle RL, Roach P. Exenatide added to insulin therapy: a retrospective review of clinical practice over two years in an academic endocrinology outpatient setting. Clin Ther. 2009;31:1511-1523.

11. Seino Y, Kaneko S, Fukuda S, et al. Combination therapy with liraglutide and insulin in Japanese patients with type 2 diabetes: a 36-week, randomized, double-blind, parallel-group trial. $J$ Diabetes Investig. 2016;7:565-573.

12. Nayak UA, Govindan J, Baskar V, Kalupahana D, Singh BM. Exenatide therapy in insulin-treated type 2 diabetes and obesity. QJM. 2010;103:687-694. 
13. Lind $\mathbf{M}$, Hirsch IB, Tuomilehto J, et al. Liraglutide in people treated for type 2 diabetes with multiple daily insulin injections: randomised clinical trial (MDI Liraglutide trial). BMJ. 2015;351:h5364.

14. Lane W, Weinrib S, Rappaport J, Hale C. The effect of addition of liraglutide to high-dose intensive insulin therapy: a randomized prospective trial. Diabetes Obes Metab. 2014;16:827-832.

15. Pantalone KM, Faiman C. Liraglutide effective in the severely insulin-resistant patient with type 2 diabetes requiring U-500 insulin: a case report. Diabetes Technol Ther. 2013;15:342-343.
16. Lane W, Weinrib S, Rappaport J. The effect of liraglutide added to U-500 insulin in patients with type 2 diabetes and high insulin requirements. Diabetes Technol Ther. 2011;13:592-595.

17. Davies ML, Pham DQ, Drab SR. GLP 1-RA add-on therapy in patients with type 2 diabetes currently on a bolus containing insulin regimen. Pharmacotherapy. 2016;36:893-905.

18. Buse JB, Bergenstal RM, Glass LC, et al. Use of twice-daily exenatide in basal insulin-treated patients with type 2 diabetes: a randomized, controlled trial. Ann Intern Med. 2011;154:103-112. 
Reproduced with permission of copyright owner. Further reproduction prohibited without permission. 